\title{
Utilization of Echocardiogram, Carotid Ultrasound, and Cranial Imaging in the Inpatient Investigation of Syncope: Its Impact on the Diagnosis and the Patient's Length of Hospitalization
}

\author{
Glenmore Lasamª, b, c, Jaimin Dudhia ${ }^{\mathrm{b}}$, Sharen Anghel ${ }^{\mathrm{b}}$, Jeffrey Brensilver ${ }^{\mathrm{b}}$
}

\begin{abstract}
Background: Although guidelines suggest that the best strategy for evaluating syncope is clinical history and physical examination, the inappropriate utilization of diagnostic imaging is common.

Methods: A single center retrospective analysis conducted in adult patients admitted for evaluation and management of syncope for a period of 12 months. Charts were reviewed to abstract demographic data, admitting and discharge diagnosis, diagnostic investigatory tests including imaging modalities (echocardiogram, carotid ultrasound, and cranial computed tomography (CT)) ordered, subspecialty consultation requested, treatment rendered and hospital length of stay (LOS).

Results: A total of 109 patients were admitted for syncope, mean age was $68.74 \pm 21.04$ years and $39.44 \%$ were men. Echocardiogram, carotid ultrasound, and cranial CT were ordered in $69.72 \%$, $33.02 \%$, and $76.14 \%$ respectively. The mean hospital LOS was 2.6 days. Patients with no imaging test, one imaging test, two imaging tests, and three imaging tests ordered have an average hospital LOS of 2.22 days, 2.44 days, 2.58 days, and 3.07 days respectively. The number of imaging test and its relation to the admitting (Chi-square (chi-sq) $\mathrm{P}=0.4165$, nominal logistic regression (LR) $\mathrm{P}=0.939$ ) and discharge (chi-sq P $=0.1507$, nominal LR $P=0.782$ ) diagnosis as well as the LOS in relation to the number of imaging test ordered (analysis of variance (ANOVA) $\mathrm{P}=0.368$, Kruskal Wallis $(\mathrm{KW}) \mathrm{P}=$ 0.352 ) were not statistically significant although there was a trend of prolonged hospital LOS the more imaging diagnostic test had been ordered. Syncope was the admitting and discharge diagnosis in $89.9 \%$ and $91.74 \%$ respectively.
\end{abstract}

Conclusions: Choosing the appropriate diagnostic tests as dictated

Manuscript submitted June 23, 2018, accepted July 5, 2018

${ }^{a}$ Morristown Medical Center, Morristown, NJ 07960, USA

b Overlook Medical Center, Summit, NJ 07901, USA

${ }^{\mathrm{c}}$ Corresponding Author: Glenmore Lasam, Department of Medicine, Overlook

Medical Center, 99 Beauvoir Avenue, Summit, NJ 07901 USA.

Email: glenmore_md@yahoo.com

doi: https://doi.org/10.14740/cr751w by the patient's clinical manifestation and utilizing less expensive test would be appropriate and cost-effective approach in appraising patients with syncope.

Keywords: Syncope; Imaging; Length of hospitalization

\section{Introduction}

Syncope is a sudden temporary loss of consciousness and associated with inability to support postural tone with quick spontaneous recovery that is generally the result of cerebral hypoperfusion [1]. It is a common condition, which accounts $1 \%$ to $2 \%$ of emergency department visit [2]. The US Department of Human and Health Services' Healthcare Cost and Utilization Project reported a \$ 3.7 billion annual aggregate charge for syncope with a mean cost of 6,647 per admission [3]. Thirty to forty percent of syncope patients are admitted for additional test which translated to an annual expenditure of $\$ 2.4$ billion as documented in the USA Medicare Database [4]; and much of these costs are directly linked to the diagnostic testing implemented to detect the causes of syncope [5]. Endeavors to diminish nonessential and costly admission have included clinical decision tools regarding the decision to admit, but have not determined the benefit and yield of testing in syncope [6].

The objective of the study is to determine the utilization of echocardiogram, carotid ultrasound, and cranial computed tomography (CT) and its impact on the admitting and discharge diagnosis in patients admitted for syncope as well as to establish if the length of their hospital stay had been affected by these investigatory imaging tests.

\section{Materials and Methods}

A single center retrospective analysis was conducted in adult patients admitted for evaluation and management of syncope at Atlantic Health System's (AHS) Overlook Medical Center from January 2015 to December 2015. Charts were reviewed to abstract demographic data, admitting and discharge diagno- 
sis, diagnostic investigatory test ordered, subspecialty consultation requested, and treatment rendered. Imaging modalities ordered that included echocardiogram, carotid ultrasound, and cranial CT were also abstracted as well as the hospital LOS. This study was approved by the AHS Institutional Review Board and was conducted according to the institutional guidelines and standards.

\section{Statistical analysis}

Values are expressed as mean \pm standard deviation (SD). Chisquare (chi-sq) and nominal logistic regression (nominal LR) were utilized to see the association of number of imaging test ordered in relation to the admitting and discharge diagnosis. Analysis of variance (ANOVA) and Kruskal Wallis (KW) were utilized to compare the mean and median data distribution respectively to determine the association of number of imaging test ordered in relation to hospital LOS. A statistically significant level was set at 0.05 .

\section{Results}

A total of 109 patients were admitted for syncope from January 1, 2015 to December 31, 2015. The mean age was 68.74 \pm 21.04 years, $60.55 \%$ were women while $39.44 \%$ were men. Whites comprised $66.05 \%$ of the admissions followed by Blacks (16.51\%), Hispanics (11.92\%), and Asians (3.66\%). Hypertension (63.30\%), hyperlipidemia (32.11\%), and coronary artery disease $(20.18 \%)$ were the leading comorbidities. Statin (33.94\%), antiplatelet (33.94\%), and beta blocker (33.02\%) comprised the most common medications taken (Table 1). Orthostatic vital signs were done in $41.28 \%$ of patients (51.11\% were positive). Telemetry and electrocardiogram (ECG) were ordered in $97.24 \%$ of patients in which normal sinus rhythm has been documented in $80.18 \%$ and $68.86 \%$ respectively. Also, electroencephalogram was ordered in $44.95 \%$ in which $95.91 \%$ have been negative. Nuclear stress test and tilt table test were ordered in 3.66\% (100\% negative) and $2.75 \%$ (33.33\% positive) of patients respectively (Table 2). Echocardiogram, carotid ultrasound, and cranial CT were ordered in $69.72 \%, 33.02 \%$, and $76.14 \%$ respectively. Cranial imaging revealed normal results in $67.46 \%$, microvascular disease in $20.48 \%$, and chronic basal ganglia infarct in $6.02 \%$ of patients. Carotid ultrasound showed normal results in $86.11 \%$ of patients. Echocardiogram documented a mean EF of $56.81 \pm 7.82 \%$, diastolic dysfunction in $46.68 \%$, concentric hypertrophy in $35.52 \%$, and normal results in $18.42 \%$ of patients (Table 3). Intravenous fluid had been administered in $41(37.61 \%)$ patients while no intravenous fluid had been ordered in $68(62.38 \%)$ of patients. Cardiology (54.12\%), epilepsy $(31.19 \%)$, neurology $(26.60 \%)$ and physiatry $(5.50 \%)$ consults were requested for these patients. Discharge medications were the same from home medications in $74.31 \%$, was revised in $22.01 \%$, and no home medications were ordered in $3.66 \%$ of patients. The mean hospital length of stay (LOS) was 2.6 days. Patients with no imaging test, one imaging test, two
Table 1. Baseline Characteristics, Comorbidities, and Home Medications of Patients Admitted for Syncope

\begin{tabular}{|c|c|}
\hline & $\mathrm{N}=109(\%)$ \\
\hline Age & $68.74 \pm 21.04$ years \\
\hline Male & $43(39.44 \%)$ \\
\hline Female & $66(60.55 \%)$ \\
\hline \multicolumn{2}{|l|}{ Race } \\
\hline White & $72(66.05 \%)$ \\
\hline Black & $18(16.51 \%)$ \\
\hline Hispanic & $13(11.92 \%)$ \\
\hline Asian & $4(3.66 \%)$ \\
\hline Other & $2(1.83 \%)$ \\
\hline \multicolumn{2}{|l|}{ Common Comorbidities } \\
\hline Hypertension & $69(63.30 \%)$ \\
\hline Hyperlipidemia & $35(32.11 \%)$ \\
\hline Coronary artery disease & $22(20.18 \%)$ \\
\hline Hypothyroidism & $18(16.82 \%)$ \\
\hline Diabetes mellitus & $17(15.59 \%)$ \\
\hline Atrial fibrillation & $15(16.51 \%)$ \\
\hline Anemia & $15(13.76 \%)$ \\
\hline Cerebrovascular accident & $11(10.09 \%)$ \\
\hline Chronic kidney disease & $11(10.09 \%)$ \\
\hline Dementia & $11(10.09 \%)$ \\
\hline \multicolumn{2}{|l|}{ Common Medications } \\
\hline Statin & $37(33.94 \%)$ \\
\hline Antiplatelet & $37(33.94 \%)$ \\
\hline Beta blocker & $36(33.02 \%)$ \\
\hline Calcium channel blocker & $32(29.35 \%)$ \\
\hline Multivitamins & $23(21.10 \%)$ \\
\hline Angiotensin converting enzyme inhibitor & $22(20.18 \%)$ \\
\hline Selective serotonin reuptake inhibitor & $20(18.34 \%)$ \\
\hline Thyroid hormone & $19(17.43 \%)$ \\
\hline Angiotensin receptor block & $15(13.76 \%)$ \\
\hline Anticonvulsant & $13(11.92 \%)$ \\
\hline
\end{tabular}

imaging tests, and three imaging tests ordered have an average hospital LOS of 2.22 days, 2.44 days, 2.58 days, and 3.07 days respectively (Table 4 and Figure 1). The number of imaging test ordered in association to LOS (ANOVA P $=0.368, \mathrm{KW}$ $\mathrm{P}=0.352)$ as well as the number of imaging test ordered and its relation to the admitting (chi-sq P $=0.4165$, nominal LR $\mathrm{P}=0.939$ ) and discharge (chi-sq $\mathrm{P}=0.1507$, nominal LR $\mathrm{P}$ $=0.782$ ) diagnosis were not statistically significant although there was a trend of prolonged hospital LOS the more imaging diagnostic test had been ordered (Tables 5-7). Syncope was the admitting and discharge diagnosis in $89.9 \%$ and $91.74 \%$ respectively (Table 8). Eighty seven percent of the patients were discharged home. 
Table 2. Investigatory Studies Ordered and Performed for Patients Admitted for Syncope and Its Results

\begin{tabular}{|c|c|}
\hline & $\mathrm{N}=109(\%)$ \\
\hline \multicolumn{2}{|l|}{ Orthostatic vital signs } \\
\hline Done & $45(41.28 \%)$ \\
\hline Positive & $23(51.11 \%)$ \\
\hline Not done & $64(58.71 \%)$ \\
\hline \multicolumn{2}{|l|}{ Telemetry } \\
\hline Ordered & $106(97.24 \%)$ \\
\hline Normal sinus rhythm & $85(80.18 \%)$ \\
\hline Sinus bradycardia & $14(13.20 \%)$ \\
\hline Bundle branch block & $14(13.20 \%)$ \\
\hline First degree atrioventricular block & $10(9.43 \%)$ \\
\hline Atrial fibrillation/flutter & $7(6.60 \%)$ \\
\hline Premature atrial contraction & $3(2.83 \%)$ \\
\hline Paced rhythm & $3(2.83 \%)$ \\
\hline Nonsustained ventricular tachycardia & $3(2.83 \%)$ \\
\hline Supraventricular tachycardia & $1(0.94 \%)$ \\
\hline Sinus arrhythmia & $1(0.94 \%)$ \\
\hline Sinus tachycardia & $1(0.94 \%)$ \\
\hline Not ordered & $3(2.83 \%)$ \\
\hline \multicolumn{2}{|l|}{ Electrocardiogram } \\
\hline Ordered & $106(97.24 \%)$ \\
\hline Normal sinus rhythm & $73(68.86 \%)$ \\
\hline Sinus bradycardia & $13(12.26 \%)$ \\
\hline Right bundle branch block & $13(12.26 \%)$ \\
\hline Nonspecific ST wave changes & $10(9.43 \%)$ \\
\hline Left ventricular hypertrophy & $10(9.43 \%)$ \\
\hline First degree atrioventricular block & $8(7.54 \%)$ \\
\hline Premature atrial contraction & $7(6.60 \%)$ \\
\hline Atrial fibrillation/flutter & $7(6.60 \%)$ \\
\hline Sinus tachycardia & $6(5.66 \%)$ \\
\hline Premature ventricular contraction & $6(5.66 \%)$ \\
\hline Sinus arrhythmia & $5(4.71 \%)$ \\
\hline Poor R wave progression & $5(4.71 \%)$ \\
\hline Left bundle branch block & $4(3.77 \%)$ \\
\hline Left anterior fascicular block & $4(3.77 \%)$ \\
\hline Intraventricular conduction delay & $4(3.77 \%)$ \\
\hline Lateral wall ischemia & $3(2.83 \%)$ \\
\hline Left atrial enlargement & $2(1.88 \%)$ \\
\hline Anterolateral wall ischemia & $1(0.94 \%)$ \\
\hline Old inferior wall myocardial infarction & $1(0.94 \%)$ \\
\hline Prolonged QT interval & $1(0.94 \%)$ \\
\hline Not ordered & $3(2.83 \%)$ \\
\hline Electroencephalogram & \\
\hline
\end{tabular}

Table 2. Investigatory Studies Ordered and Performed for Patients Admitted for Syncope and Its Results - (continued)

\begin{tabular}{|cl}
\hline & $\mathbf{N}=\mathbf{1 0 9}(\mathbf{\%})$ \\
\hline Ordered & $49(44.95 \%)$ \\
Negative & $47(95.91 \%)$ \\
Positive & $2(4.08 \%)$ \\
Primary generalized epilepsy & $1(50 \%)$ \\
Left temporal region epilepsy & $1(50 \%)$ \\
\hline Nuclear stress test & \\
\hline Ordered & $4(3.66 \%)$ \\
Positive & $0(0 \%)$ \\
Negative & $4(100 \%)$ \\
\hline Tilt table test & $3(2.75 \%)$ \\
Ordered & $1(33.33 \%)$ \\
Positive & $2(66.66 \%)$ \\
Negative & \\
\hline Intracardiac loop recorder placement & $5(4.58 \%)$ \\
\hline Ordered & \\
\hline Pacemaker interrogation & $2(1.83 \%)$ \\
\hline Ordered & $0(0 \%)$ \\
\hline Electrophysiological studies & \\
\hline Ordered & \\
\hline
\end{tabular}

\section{Discussion}

The recommended strategy for determining the etiology of syncope is clinical evaluation with history, physical examination, and orthostatic blood pressure (BP) measurement. When the initial cause remains unclear, further investigation is appropriate. Several algorithms have been developed by specialty organizations to determine the cause of syncope but no single protocol had established its cause which translates to unnecessary utilization of test including imaging modalities to evaluate syncope. The 2018 European Society of Cardiology (ESC) guidelines for the diagnosis and management of syncope recommended that the initial evaluation of the patient presenting with transient loss of consciousness should include careful history, physical examination (including orthostatic BP measurement), and ECG which can establish the etiology of syncope in most patients, thus, enabling no further evaluation needed and instead institute planned treatment when the diagnosis is nearly evident or highly possible [7]. Also, the 2017 American College of Cardiology/American Heart Association/Heart Rhythm Society (ACC/AHA/HRS) guideline for the evaluation and management of patients with syncope recommended detailed history, physical examination (including orthostatic BP measurement), and ECG in the initial evaluation of syncope [1].

Initial evaluation is able to define the cause of syncope in $23-50 \%$ of patients $[8,9]$. In some circumstances, the initial evaluation does not unravel a definite diagnosis but rather sug- 
Table 3. Imaging Studies Ordered and Performed for Patients Admitted for Syncope and Its Results

\begin{tabular}{|c|c|}
\hline & $\mathrm{N}=109(\%)$ \\
\hline \multicolumn{2}{|l|}{ Cranial computed tomography } \\
\hline Ordered & $83(76.14 \%)$ \\
\hline Normal & $56(67.46 \%)$ \\
\hline Microvascular disease & $17(20.48 \%)$ \\
\hline Chronic basal ganglia infarct & $5(6.02 \%)$ \\
\hline Hematoma & $2(2.40 \%)$ \\
\hline Meningioma & $2(2.40 \%)$ \\
\hline Chronic ischemic changes & $1(1.20 \%)$ \\
\hline Central cortical atrophy & $1(1.20 \%)$ \\
\hline Parenchymal volume loss & $1(1.20 \%)$ \\
\hline Calcification & $1(1.20 \%)$ \\
\hline Nonspecific white matter changes & $1(1.20 \%)$ \\
\hline Small intraparenchymal hemorrhage & $1(1.20 \%)$ \\
\hline Basal ganglia neuroepithelial cyst & $1(1.20 \%)$ \\
\hline Cavernous malformation & $1(1.20 \%)$ \\
\hline Hemorrhagic contusion & $1(1.20 \%)$ \\
\hline Acute Maxillary sinusitis & $1(1.20 \%)$ \\
\hline Not ordered & $26(23.85 \%)$ \\
\hline \multicolumn{2}{|l|}{ Carotid ultrasound } \\
\hline Ordered & $36(33.02 \%)$ \\
\hline Normal & $31(86.11 \%)$ \\
\hline Proximal ICA bilateral stenosis $(60-79 \%)$ & $1(2.77 \%)$ \\
\hline Proximal ICA bilateral stenosis (40-59\%) & $1(2.77 \%)$ \\
\hline Right ICA stenosis $(80-89 \%)$ & $1(2.77 \%)$ \\
\hline Bilateral stenosis ICA (40-59\%) & $1(2.77 \%)$ \\
\hline Left ICA mild to moderate plaque & $1(2.77 \%)$ \\
\hline Not ordered & $73(66.97 \%)$ \\
\hline \multicolumn{2}{|l|}{ Echocardiogram } \\
\hline Ordered & $76(69.72 \%)$ \\
\hline Diastolic dysfunction & $37(46.68 \%)$ \\
\hline Concentric hypertrophy & $27(35.52 \%)$ \\
\hline Normal & $14(18.42 \%)$ \\
\hline Mild mitral regurgitation & $12(15.78 \%)$ \\
\hline Mild tricuspid regurgitation & $9(11.84 \%)$ \\
\hline Mitral annulus calcification & $8(10.52 \%)$ \\
\hline Moderate to severe mitral regurgitation & $8(10.52 \%)$ \\
\hline Mild Aortic regurgitation & $5(6.57 \%)$ \\
\hline Moderate aortic regurgitation & $5(6.57 \%)$ \\
\hline Moderate aortic stenosis & $5(6.57 \%)$ \\
\hline Moderate tricuspid regurgitation & $5(6.57 \%)$ \\
\hline Mild aortic stenosis & $4(5.26 \%)$ \\
\hline Mild pulmonary hypertension & $4(5.26 \%)$ \\
\hline
\end{tabular}

Table 3. Imaging Studies Ordered and Performed for Patients Admitted for Syncope and Its Results - (continued)

\begin{tabular}{|ll|}
\hline & $\mathbf{N}=\mathbf{1 0 9}(\mathbf{\%})$ \\
\hline Mild left ventricular hypertrophy & $4(5.26 \%)$ \\
\hline Mild bilateral atrial enlargement & $4(5.26 \%)$ \\
\hline Moderate pulmonary hypertension & $2(2.63 \%)$ \\
\hline Severe right atrial enlargement & $2(2.63 \%)$ \\
\hline Mild to moderate global hypokinesis & $2(2.63 \%)$ \\
\hline Bioprosthetic valve & $2(2.63 \%)$ \\
\hline Severe tricuspid regurgitation & $1(1.31 \%)$ \\
\hline Speckled pattern & $1(1.31 \%)$ \\
\hline Severe pulmonary hypertension & $1(1.31 \%)$ \\
\hline Mild pericardial effusion & $1(1.31 \%)$ \\
Mild mitral stenosis & $1(1.31 \%)$ \\
\hline Severe aortic stenosis & $1(1.31 \%)$ \\
\hline Mild asymmetric hypertrophy & $1(1.31 \%)$ \\
\hline Basal septum hypokinesis & $1(1.31 \%)$ \\
Mild aortic root dilation & $1(1.31 \%)$ \\
Mild basal septal hypertrophy & $1(1.31 \%)$ \\
Primum atrial septal defect & $1(1.31 \%)$ \\
Paramembranous ventricular septal defect & $1(1.31 \%)$ \\
Endocardial cushion defect & $1(1.31 \%)$ \\
Not ordered & $33(30.27 \%)$ \\
\hline
\end{tabular}

ICA: internal carotid artery.

gests other etiologies which necessitate additional diagnostic testing that assess the risk of major cardiovascular events or sudden cardiac death. Investigatory modalities including cardiac enzymes tests, CT scans, echocardiography, carotid ultrasonography, and electroencephalography all affected diagnosis or management in less than $5 \%$ of cases and helped determine the etiology of syncope less than $2 \%$ of the time; however, postural BP recording, performed in only $38 \%$ of episodes, had the highest yield with respect to affecting diagnosis $(18 \%-26 \%)$ or management $(25 \%-30 \%)$ and determining etiology of the syncopal episode $(15 \%-21 \%)$ [10].

Cardiac imaging performed routinely is not beneficial in the appraisal of patients with syncope unless a cardiac cause is uncertain based on findings on initial evaluation that includes history, physical examination, or ECG $[11,12]$. Echocardiography plays an essential function in risk stratification and serves to validate or contradict the uncertainties for the patients with suspected heart disease [13]; however, it establishes the etiology of syncope in very few patients when no further tests are required [14]. A syncope retrospective study documented that echocardiography proposed a cardiac syncope diagnosis in $48 \%$ of study patients [12]. On the other hand in a prospective syncope study, echocardiography suggested critical valvular disease or compromised left ventricular systolic function as the etiology of syncopal event in $22 \%$ of patients [6]. Albeit echocardiography may never be capable to determine the 
Table 4. Number of Imaging Test Ordered for Patients Admitted for Syncope and Its Impact on the Hospital Length of Stay

\begin{tabular}{lll} 
& $\mathbf{N}(\%)$ & Length of stay in days \\
\hline No imaging test ordered & $9(8.25 \%)$ & 2.22 \\
One imaging test ordered & $27(24.77 \%)$ & 2.44 \\
Two imaging tests ordered & $46(42.20 \%)$ & 2.58 \\
Three imaging tests ordered & $27(24.77 \%)$ & 3.07 \\
\hline
\end{tabular}

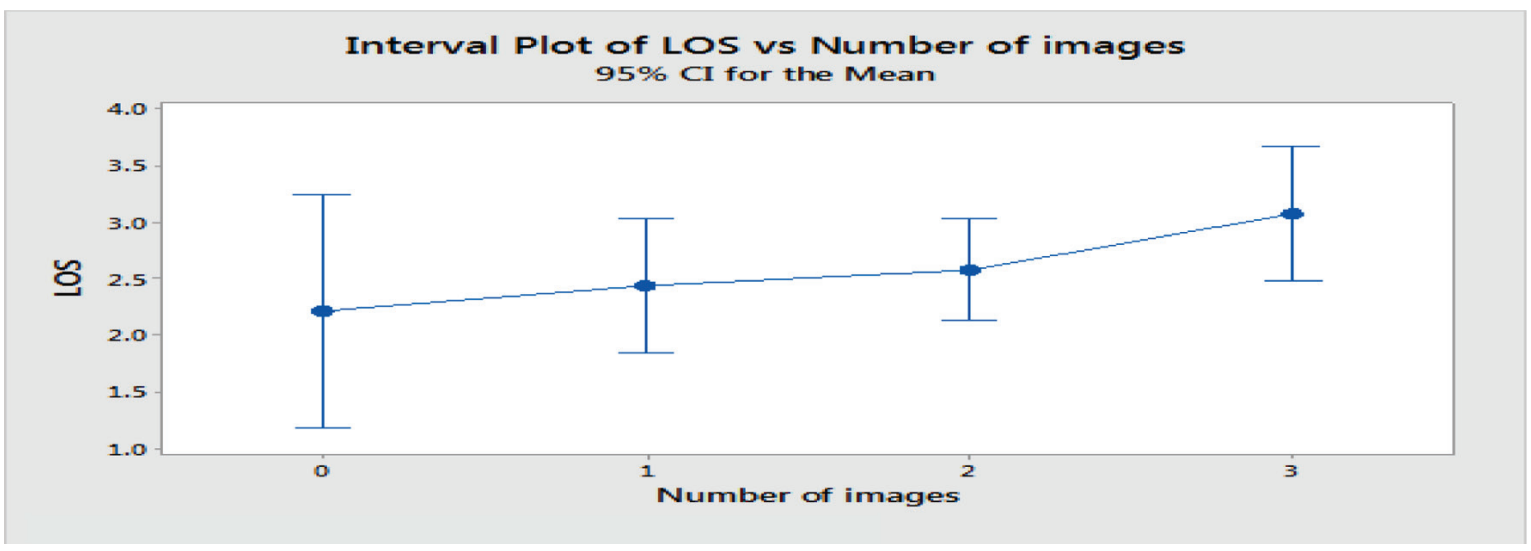

Figure 1. Interval plot of hospital length of stay (LOS) in correlation with number of imaging test ordered. LOS: length of stay. The pooled standard deviation was used to calculate the intervals.

proximate syncopal etiology, it contributes knowledge for a conceivable disease burden linked to outcome. Cranial MRI and CT are not advocated in the conventional evaluation of patients with syncope in the lack of focal neurological deficit or head trauma that aid additional investigation $[15,16]$. A retrospective study that obtained cranial CT scan in patients with syncope provided diagnosis in $2 \%$ of patients [17] while a prospective study that utilized cranial CT scan in patients with syncope yielded abnormal results in 5\% of patients [18]. Also, imaging of the carotid is not endorsed as well in the customary syncope evaluation in the dearth of focal neurological findings that substantiate more investigation since this approach determined a diagnosis only in $0.5 \%$ of patients $[11,15,16,19,20]$.

In our study, cranial CT scan, echocardiography, carotid ultrasonography all affected the diagnosis in $2 \%$ of cases, have low diagnostic yield in determining the etiology of syncope, prolonged the hospital LOS, and were costly. A previous study documented an average of 4.7 days LOS for admitted syncope patients [21] while another one documented an average of 3 days which correlated with number of predictors such as age,

Table 5. Number of Imaging Test Ordered (Echocardiogram, Carotid Ultrasound, and Cranial Computed Tomography) and Its Association to Patient's Hospital Length of Stay

\begin{tabular}{|c|c|c|c|c|c|c|}
\hline Hospital length of stay & 0 test $(\mathrm{N}=9)$ & 1 test $(\mathrm{N}=27)$ & 2 tests $(\mathrm{N}=46)$ & 3 tests $(\mathrm{N}=27)$ & P (ANOVA) & $\mathrm{P}(\mathrm{KW})$ \\
\hline Mean \pm SD & $2.222 \pm 1.481$ & $2.444 \pm 1.396$ & $2.587 \pm 1.627$ & $3.074 \pm 1.639$ & 0.368 & \\
\hline Median(minimum - maximum) & $1(1-4)$ & $2(1-7)$ & $2(1-6)$ & $3(1-7)$ & & 0.352 \\
\hline
\end{tabular}

Table 6. Number of Imaging Test Ordered (Echocardiogram, Carotid Ultrasound, and Cranial Computed Tomography) and Its Influence on Admitting Diagnosis

\begin{tabular}{lllll}
\hline Number of imaging test ordered & Syncope & Vasovagal syncope & Syncope vs. seizure & Total \\
\hline 0 & $7(8.092)$ & $1(0.330)$ & $1(0.578)$ & 9 \\
1 & $22(24.275)$ & $2(0.991)$ & $2(1.734)$ & 27 \\
2 & $43(41.358)$ & $1(1.688)$ & $1(1.734)$ & 46 \\
3 & $26(24.275)$ & $0(0.991)$ & 7 & 109 \\
\hline Total & 98 & 4 & & 27 \\
\hline
\end{tabular}

Chi-square $\mathrm{P}$ value $=0.4165$, nominal logistic regression $\mathrm{P}$ value $=0.939$. 
Table 7. Number of Imaging Test Ordered (Echocardiogram, Carotid Ultrasound, and Cranial Computed Tomography) and Its Influence on Discharge Diagnosis

\begin{tabular}{|c|c|c|c|c|c|c|}
\hline $\begin{array}{l}\text { Number of imaging } \\
\text { test ordered }\end{array}$ & Syncope & Vasovagal syncope & $\begin{array}{l}\text { Neurocardiogenic } \\
\text { syncope }\end{array}$ & $\begin{array}{l}\text { Syncope with } \\
\text { seizure }\end{array}$ & $\begin{array}{l}\text { Syncope vs. } \\
\text { seizure }\end{array}$ & Total \\
\hline 0 & $8(8.2569)$ & $0(0.3303)$ & $0(0.1651)$ & $0(0.1651)$ & $1(0.0826)$ & 9 \\
\hline 2 & 43 (42.2018) & $2(1.6881)$ & $0(0.8440)$ & $1(0.8440)$ & $0(0.4220)$ & 46 \\
\hline 3 & $26(24.7706)$ & $0(0.9908)$ & $1(0.4954)$ & $0(0.4954)$ & $0(0.2477)$ & 27 \\
\hline
\end{tabular}

Chi-square $\mathrm{P}$ value $=0.1507 ;$ nominal logistic regression $\mathrm{P}$ value $=0.782$.

sex, and comorbidities [22]. Our study determined the utilization of an incremental number of imaging modalities ordered (echocardiography, cranial CT scan, and carotid ultrasound) and its impact on the hospital LOS which showed a trend towards a prolonged course although it was not statistically considerable.

\section{Limitations}

This is a small retrospective study and thus the sample size may possibly be a confounding factor to achieve a statistically significant power. There is a demand for extensive clinical trials that determine the diagnostic yield and observance of a systematic application of standardized syncope guideline.

\section{Conclusions}

Choosing the appropriate diagnostic tests as dictated by the patient's clinical manifestation and utilizing less expensive modality would be the appropriate and cost-effective approach in appraising patients with syncope.

\section{Conflict of Interest}

The authors declare that they have no conflict of interest.

Table 8. Admitting and Discharge Diagnosis of Patients Admitted for Syncope

\begin{tabular}{|ll}
\hline & $\mathbf{N}=\mathbf{1 0 9}(\mathbf{\%})$ \\
\hline Admitting diagnosis & \\
Syncope & $98(89.90 \%)$ \\
Syncope with fall & $7(6.42 \%)$ \\
Syncope vs. Seizure & $4(3.66 \%)$ \\
Discharge diagnosis & \\
Syncope & $100(91.74 \%)$ \\
Vasovagal syncope & $4(3.66 \%)$ \\
Neurocardiogenic syncope & $2(1.83 \%)$ \\
Syncope with seizure & $2(1.83 \%)$ \\
Syncope vs. Seizure & $1(0.91 \%)$ \\
\hline
\end{tabular}

\section{References}

1. Shen WK, Sheldon RS, Benditt DG, Cohen MI, Forman DE, Goldberger ZD, Grubb BP, et al. 2017 ACC/AHA/ HRS guideline for the evaluation and management of patients with syncope: a report of the American College of Cardiology/American Heart Association Task Force on clinical practice guidelines and the heart rhythm society. J Am Coll Cardiol. 2017;70(5):e39-e110.

2. Baron-Esquivias G, Martinez-Alday J, Martin A, Moya A, Garcia-Civera R, Paz Lopez-Chicharro M, MartinMendez M, et al. Epidemiological characteristics and diagnostic approach in patients admitted to the emergency room for transient loss of consciousness: Group for Syncope Study in the Emergency Room (GESINUR) study. Europace. 2010;12(6):869-876.

3. HCUPnet, Healthcare Cost and Utilization Project. Agency for Healthcare Research and Quality, Rockville, MD. https://hcupnet.ahrq.gov/. Accessed June 22, 2018.

4. Saklani P, Krahn A, Klein G. Syncope. Circulation. 2013;127(12):1330-1339.

5. Sun BC. Quality-of-life, health service use, and costs associated with syncope. Prog Cardiovasc Dis. 2013;55(4):370-375.

6. Chiu DT, Shapiro NI, Sun BC, Mottley JL, Grossman SA. Are echocardiography, telemetry, ambulatory electrocardiography monitoring, and cardiac enzymes in emergency department patients presenting with syncope useful tests? A preliminary investigation. J Emerg Med. 2014;47(1):113-118.

7. Brignole M, Moya A, de Lange FJ, Deharo JC, Elliott PM, Fanciulli A, Fedorowski A, et al. 2018 ESC Guidelines for the diagnosis and management of syncope. Eur Heart J. 2018;39(21):1883-1948.

8. Crane SD. Risk stratification of patients with syncope in an accident and emergency department. Emerg Med J. 2002;19(1):23-27.

9. Croci F, Brignole M, Alboni P, Menozzi C, Raviele A, Del Rosso A, Dinelli M, et al. The application of a standardized strategy of evaluation in patients with syncope referred to three syncope units. Europace. 2002;4(4):351355.

10. Mendu ML, McAvay G, Lampert R, Stoehr J, Tinetti ME. Yield of diagnostic tests in evaluating syncopal episodes 
in older patients. Arch Intern Med. 2009;169(14):12991305.

11. Krahn AD, Klein GJ, Norris C, Yee R. The etiology of syncope in patients with negative tilt table and electrophysiological testing. Circulation. 1995;92(7):18191824.

12. Click RL, Gersh BJ, Sugrue DD, Holmes DR, Jr., Wood DL, Osborn MJ, Hammill SC. Role of invasive electrophysiologic testing in patients with symptomatic bundle branch block. Am J Cardiol. 1987;59(8):817-823.

13. Recchia D, Barzilai B. Echocardiography in the evaluation of patients with syncope. J Gen Intern Med. 1995;10(12):649-655.

14. Sarasin FP, Junod AF, Carballo D, Slama S, Unger PF, Louis-Simonet M. Role of echocardiography in the evaluation of syncope: a prospective study. Heart. 2002;88(4):363-367.

15. Krahn AD, Klein GJ, Yee R, Takle-Newhouse T, Norris C. Use of an extended monitoring strategy in patients with problematic syncope. Reveal Investigators. Circulation. 1999;99(3):406-410.

16. Connolly SJ, Sheldon R, Roberts RS, Gent M. The North American Vasovagal Pacemaker Study (VPS). A randomized trial of permanent cardiac pacing for the prevention of vasovagal syncope. J Am Coll Cardiol. 1999;33(1):16-20.

17. Pires LA, Ganji JR, Jarandila R, Steele R. Diagnostic patterns and temporal trends in the evaluation of adult patients hospitalized with syncope. Arch Intern Med. 2001;161(15):1889-1895.

18. Grossman SA, Fischer C, Bar JL, Lipsitz LA, Mottley L, Sands K, Thompson S, et al. The yield of head CT in syncope: a pilot study. Intern Emerg Med. 2007;2(1):46-49.

19. Kinay O, Yazici M, Nazli C, Acar G, Gedikli O, Altinbas A, Kahraman H, et al. Tilt training for recurrent neurocardiogenic syncope: effectiveness, patient compliance, and scheduling the frequency of training sessions. Jpn Heart J. 2004;45(5):833-843.

20. Samniah N, Sakaguchi S, Lurie KG, Iskos D, Benditt DG. Efficacy and safety of midodrine hydrochloride in patients with refractory vasovagal syncope. Am J Cardiol. 2001;88(1):A7, 80-83.

21. Sankar V, Close S, Leslie SJ. Evidence based evaluation of syncope of uncertain origin. BJMP. 2010;3(4):a340.

22. Lin M, Wolfe RE, Shapiro NI, Novack V, Lior Y, Grossman SA. Observation vs admission in syncope: can we predict short length of stays? Am J Emerg Med. 2015;33(11):1684-1686. 